\title{
Comparative Hemodynamic Effects of Isoproterenol, Dopamine, and Dobutamine in the Newborn Dog
}

\author{
DAVID J. DRISCOLL, PAUL C. GILLETTE, ROBERT M. LEWIS, CRAIG J. HARTLEY, AND \\ ARNOLD SCHWARTZ \\ With technical assistance of Mr. Frank Dunn \\ Department of Pediatrics, Section of Cardiology, Department of Medicine, Section of Cardiovascular Sciences, Baylor \\ College of Medicine, The Methodist Hospital, and Texas Children's Hospital, Houston, Texas, USA
}

\begin{abstract}
Summary
To compare the hemodynamic effects of isoproterenol, dopamine, and dobutamine in the immature animal, each drug was infused into anesthetized open chest puppies and cardiac output was measured, as were systemic arterial blood pressure, heart rate, and renal artery blood flow.

Cardiac output was increased by dopamine and dobutamine. Isoproterenol caused a significantly greater increment of heart rate than either of the other agents to achieve a similar change of cardiac output.

Systemic arterial mean blood pressure was increased by dopamine and dobutamine, but decreased by isoproterenol.

Dopamine produced a significant increase of renal artery blood flow while renal artery blood flow was unchanged by dobutamine and decreased by isoproterenol.

\section{Speculation}

Dopamine and dobutamine may have potential advantages over isoproterenol in augmenting cardiovascular function in young animals.

Isoproterenol is the inotropic agent used most commonly for treatment of cardiogenic shock in children. Although dopamine and dobutamine have been shown to be superior to isoproterenol for therapy of cardiogenic shock in adults $(1-4,9,11,14-16$, $20-24,27-32,34)$, there have been few studies of the hemodynamic effects of these newer sympathomimetic amines in the newborn or young animal. The purpose of this study was to determine the response of the neonatal dog cardiovascular system to dopamine and dobutamine and compare these responses to those produced by isoproterenol.
\end{abstract}

\section{MATERIAL AND METHODS}

\section{EXPERIMENTAL PREPARATION}

Twenty-four puppies, ranging in age from 3-65 days (mean 19 \pm 3 SEM) and in weight from 300-2440 $\mathrm{g}$ (mean $948 \pm 136$ ) were used for this study. They were selected without preference to breed or sex.

The animals were anesthetized with sodium pentobarbital 30 $\mathrm{mg} / \mathrm{kg}$ ip. Tracheostomy was performed and ventilation was controlled using a Harvard model 606 animal respirator. Supplemental oxygen was administered via the respirator to maintain arterial $\mathrm{PO}_{2}$ greater than $100 \mathrm{mg} \mathrm{Hg}$. A tidal volume of $7-10 \mathrm{cc} /$ $\mathrm{kg}$ was used. A standard limb lead of the ECG and rectal temperature were monitored continuously. The tips of polyethylene catheters were placed into the femoral artery and vein and advanced to the abdominal aorta and right atrium. Phasic and mean central aortic blood pressure was measured using a Statham P23db pressure transducer connected to the aortic catheter. Pulsed range-gated ultrasonic doppler flow probes were placed around the ascending aorta through a midline thoracotomy and around the left renal artery through a laparotomy. After applying the flow probes, the edges of the wounds were approximated and the preparation was covered with moist sponges and a plastic sheet. Body temperature was maintained at $36-37^{\circ} \mathrm{C}$ with heating pads and lights. Arterial blood gases were measured at the completion of instrumentation and before infusion of each drug. Acid-base balance was maintained by either adjusting the respirator or by infusion of sodium bicarbonate. The preparations were allowed to equilibrate for 45-60 min after instrumentation.

When a steady state was attained, either isoproterenol, dopamine, or dobutamine was infused through the femoral venous catheter using a Harvard infusion pump. Drugs were diluted in $5 \%$ dextrose and water and infused at a rate ranging from $0.007-$ $0.19 \mathrm{cc} / \mathrm{min}$. Thus, during any drug infusion the volume of fluid infused was less than or equal to the volume of natural fluid losses. Dopamine and dobutamine were infused at doses of 2, 5, 10,20 , and $50 \mu \mathrm{g} / \mathrm{kg} / \mathrm{min}$ and isoproterenol at doses of $0.05,0.1$, $0.25,0.5$, and $1.0 \mu \mathrm{g} / \mathrm{kg} / \mathrm{min}$. Infusion of each drug was begun at the lowest dose and continued for $10 \mathrm{~min}$ before increasing the dose. Two drugs were tested in each preparation and the order of drug administration was reversed in each experiment. Phasic and mean central aortic blood pressure, phasic and mean velocity of aortic blood flow, phasic and mean velocity of renal artery blood flow, heart rate and the ECG were continuously recorded on a Brush recorder model 260 . Right atrial mean blood pressure was recorded intermittently during the drug infusion. Heart rate was measured from the ECG.

The percent of change from control was determined for each variable and used for comparing responses. The percent of change from control of systemic and renal vascular resistance was calculated by dividing the percent of change from control of the velocity of aortic or renal blood flow by the percent of change from control of systemic arterial mean blood pressure. The data were statistically analyzed using Student's $t$ test.

\section{BLOOD FLOW MEASUREMENT}

Changes in blood flow were evaluated using an ultrasonic range-gated pulsed Doppler flowmeter designed in our laboratory for use on small vessels $(17,19)$. In contrast to the continuous wave Doppler technique developed by Franklin et al. (7), the pulsed technique allows a single ultrasonic crystal to serve as both transmitter and receiver. A relatively high ultrasonic frequency of $20 \mathrm{MHz}$ produces sufficient scattering or reflection from blood cells to permit the use of ultrasonic crystals with areas less than 1 
$\mathrm{mm}^{2}$. Low profile flow probes can, thus, be constructed with lumens as small as $1.0 \mathrm{~mm}$.

The flow probes used in this study varied in size from 1-8 mm inside diameter. The probes were constructed using a " $\mathrm{C}$ " shaped epoxy body into which a blood vessel can be introduced. The single ultrasonic crystal was secured in a notch such that the sound beam entered the vessel at an angle of approximately $45^{\circ}$.

In a continuous wave or pulsed Doppler instrument the relationship between the Doppler shift frequency $(\Delta f)$ and the velocity (V) of the blood is given by the equation:

$$
\Delta \mathrm{f}=2 \mathrm{f}_{\mathrm{o}} \frac{\mathrm{V}}{\mathrm{C}} \cos \theta
$$

where $f_{o}$ is the ultrasonic frequency $(20 \mathrm{MHz})$, $c$ is the speed of sound $\left(1.5 \times 10^{5} \mathrm{~cm} / \mathrm{sec}\right)$, and $\theta$ is the angle between the sound beam and the vessel axis $\left(\sim 45^{\circ}\right)$. Because $f_{o}$, $c$, and $\theta$ are constant, $\Delta \mathrm{f}$ is directly proportional to the velocity of blood flow.

The pulsed Doppler receiver is range-gated allowing flow to be sensed at a selected distance from the ultrasonic crystal. In use, the range control was adjusted to record the highest velocity of blood flow that occurs near the center of a blood vessel. Under these conditions the probes can be calibrated against volume flow by cannulating the vessel distal to the probe and recording the instrument output as the effluent blood is time collected. Two representative calibration curves are shown (Fig. 1). Blood flow $(\mathrm{ml} / \mathrm{min})$ is related linearly to Doppler shift frequency $(\mathrm{kHz})$.

In this study, the change in flow as opposed to absolute volume flow was the major interest. Thus, zero stability, linearity, and reproducibility are more important than the scale factor relating the Doppler frequency shift to volume flow. Because it was not possible to calibrate every probe each time it was used, the flow data will be presented in terms of the Doppler frequency shift. The accuracy of the instrumentation in determining frequency shifts was verified by injecting signals of a known frequency using a Wavetek model 144 signal generator and a Monsanto model 100B frequency counter. Because zero Doppler frequency shift corresponds absolutely to zero flow, the zero stability was verified periodically by switching off the audio input to the frequency counting circuitry of the pulsed Doppler. The nominal sensitivity of the pulsed Doppler is 0.25 volts/ $\mathrm{KHz}$ of the Doppler shift. The output is bidirectional so that any flow reversals are properly displayed. A multichannel version allows flow to be evaluated in several vessels simultaneously without interference (18).
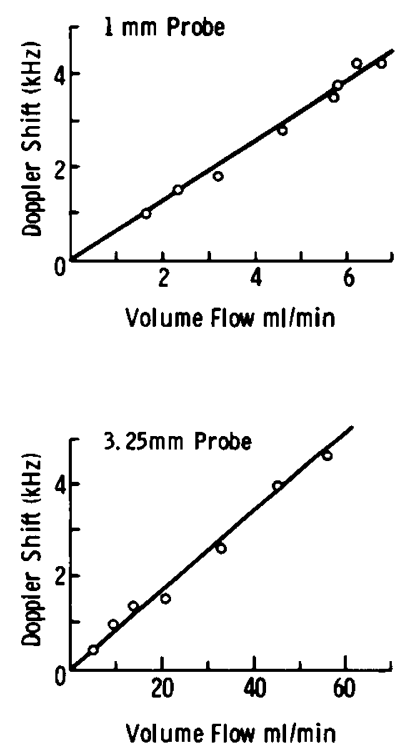

Fig. 1. In vivo calibration of a $1 \mathrm{~mm}$ (top) and $3.5 \mathrm{~mm}$ (bottom) internal diameter pulsed range-gated ultrasonic Doppler flow probe. Volume flow (abscissa) was measured by the timed volume collection technique and recorded simultaneously with mean Doppler shift (ordinate) at different levels of flow.

\section{RESULTS}

Isoproterenol significantly reduced systemic arterial mean blood pressure from control $(P<0.05)$ and increased heart rate $(P<$ 0.05 ; Fig. 2). Cardiac output was unchanged from control by isoproterenol while renal artery blood flow was decreased significantly $(P<0.05$; Fig. 2$)$. Whereas isoproterenol did not affect systemic vascular resistance, renal vascular resistance increased from control $(P<0.1)$ at 0.5 and $1 \mu \mathrm{g} / \mathrm{kg} / \mathrm{min}$ of isoproterenol (Fig. 3).

Dopamine significantly increased systemic arterial mean blood pressure from control $(P<0.05)$ and increased heart rate $(P<$ 0.05 ; Fig. 2). Cardiac output was increased from control by dopamine $(P<0.1$; dose $=10$ and $50 \mu \mathrm{g} / \mathrm{kg} / \mathrm{min} ;$ Fig. 2). Renal artery blood flow was increased from control $(P<0.05$ and $P<$ 0.1 ) at $5,10,20$, and $50 \mu \mathrm{g} / \mathrm{kg} / \mathrm{min}$ of dopamine (Fig. 2). Dopamine increased systemic vascular resistance $(P<0.05$ and 0.1$)$ at high doses $(20$ and $50 \mu \mathrm{g} / \mathrm{kg} / \mathrm{min}$ ) whereas renal vascular resistance was unchanged from control at all doses of dopamine (Fig. 3).

Dobutamine increased systemic arterial mean blood pressure from control $(P<0.1)$ at $20 \mu \mathrm{g} / \mathrm{kg} / \mathrm{min}$ and increased heart rate $(P<0.05$; Fig. 2). Cardiac output was increased from control by dobutamine $(P<0.1)$ at $50 \mu \mathrm{g} / \mathrm{kg} / \mathrm{min}$ whereas renal artery blood flow was unchanged from control at all doses of dobutamine (Fig. 2). Whereas dobutamine did not effect systemic vascular resistance, renal vascular resistance increased from control $(P<0.1)$ at 20 and $50 \mu \mathrm{g} / \mathrm{kg} / \mathrm{min}$ of dobutamine (Fig. 3).
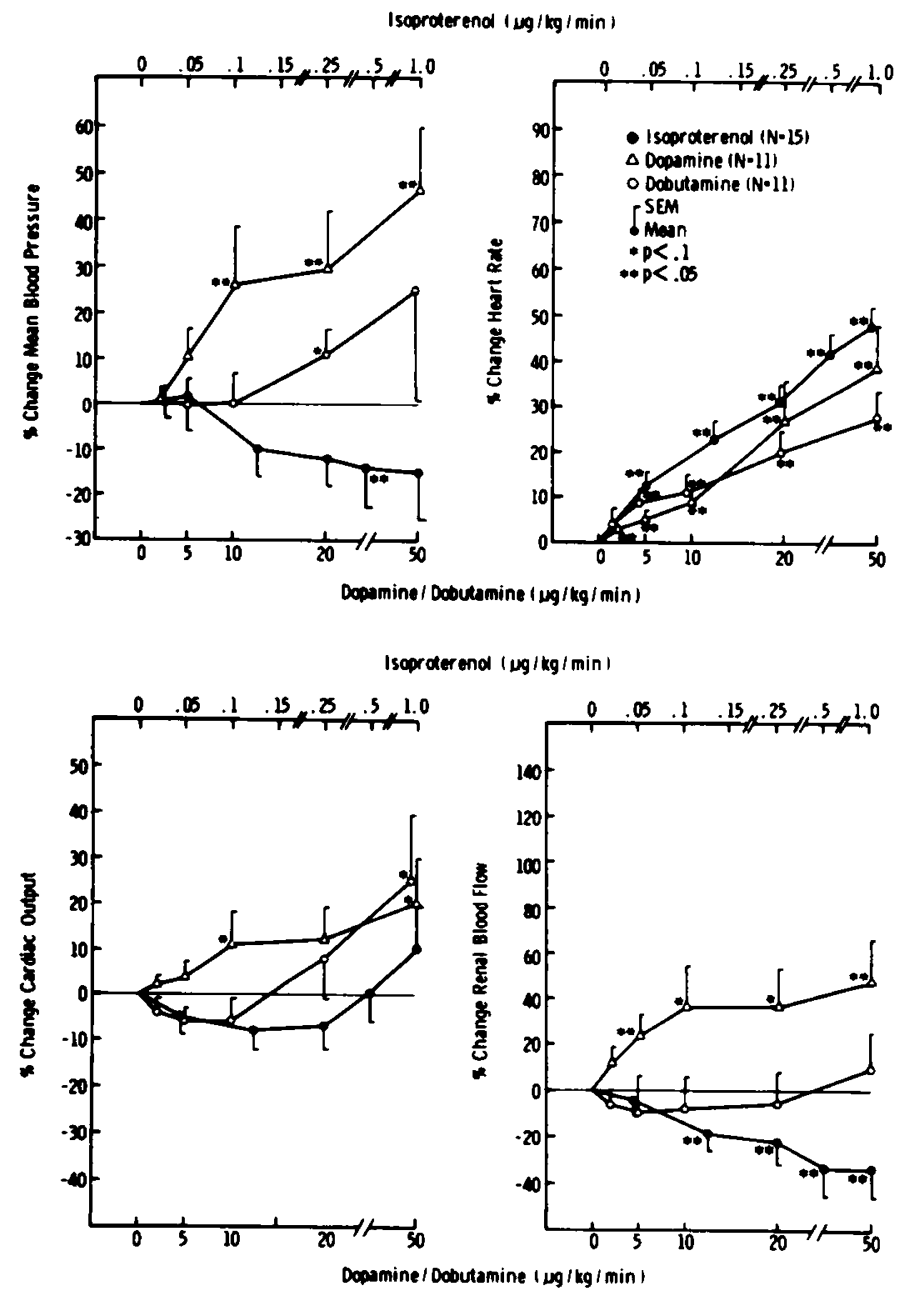

Fig. 2. Comparison of the cardiovascular response of puppies ages 365 days (mean $=19 \pm 3$ days) to three inotropic agents: isoproterenol, dopamine, and dobutamine. Asterisks indicate significant changes from control for each drug tested. 
At the dose of each of the three drugs that resulted in a $10 \%$ mean increase from control of cardiac output, heart rate was increased significantly more by isoproterenol than by either dopamine or dobutamine; central aortic mean blood pressure was increased significantly more by dopamine and dobutamine than by isoproterenol; and renal artery blood flow was decreased by isoproterenol and unchanged by dobutamine, but was increased by dopamine (Fig. 4).

At the dose of each of the three drugs that resulted in a $20 \%$ increase from control in heart rate, cardiac output was increased by dopamine and dobutamine, but was unchanged from control by isoproterenol; renal artery blood flow was increased by dopamine, but was decreased from control by isoproterenol and unchanged from control by dobutamine; and central aortic mean blood pressure was increased more by dopamine than by dobutamine or isoproterenol (Fig. 5).

Control arterial mean blood pressure and heart rate were similar for each group of experiments (Table 1). Right atrial mean blood

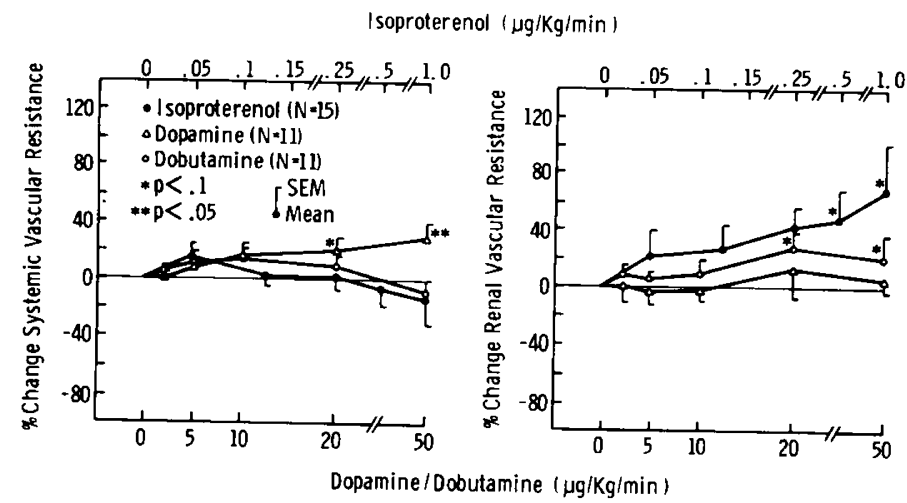

Fig. 3. Comparison of the response of systemic and renal vascular resistance of puppies ages 3-65 days (mean $=19 \pm 3$ days) to isoproterenol, dopamine, and dobutamine. Asterisks indicate significant changes from control for each drug tested.

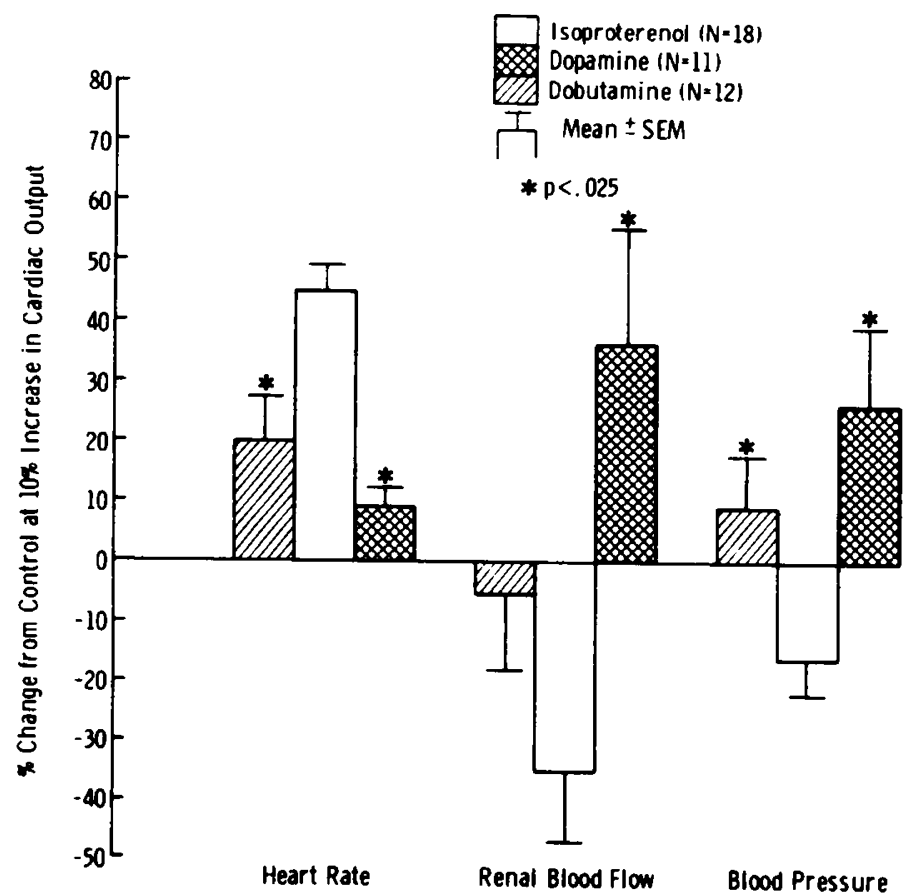

Fig. 4. Comparison of the response of heart rate, renal artery blood flow, and aortic blood pressure in puppies ages 3-65 days (mean $=19 \pm$ 3 days) to isoproterenol, dopamine, and dobutamine. The dose of each drug selected for comparison is that dose at which cardiac output was increased $10 \%$ from control. Asterisks indicate significant differences between isoproterenol and dopamine or isoproterenol and dobutamine.

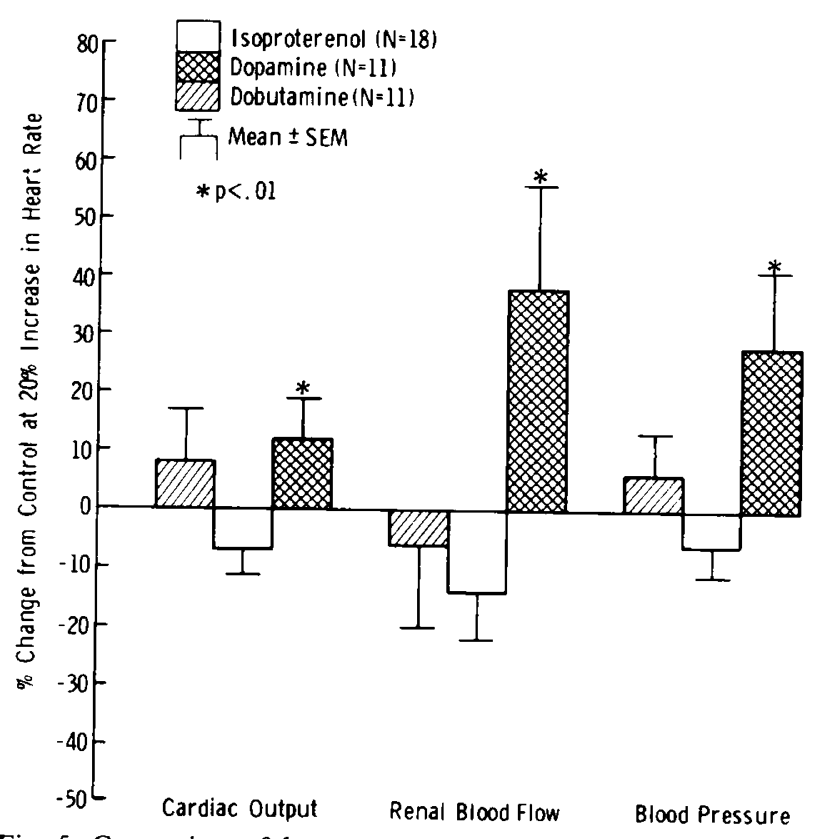

Fig. 5. Comparison of the response of cardiac output, renal blood flow, and aortic blood pressure in puppies ages 3-65 days (mean $=19 \pm 3$ days) to isoproterenol, dopamine, and dobutamine. The dose of each drug selected for comparison is that dose at which heart rate was increased $20 \%$ from control. Asterisks indicate significant differences between isoproterenol and dopamine, or isoproterenol and dobutamine.

Table 1. Control values, all puppies ${ }^{1}$

\begin{tabular}{lcc}
\hline & $\begin{array}{c}\text { Mean BP } \\
(\mathrm{mm} \mathrm{Hg})\end{array}$ & $\begin{array}{c}\text { Heart rate } \\
\text { (beat/min) }\end{array}$ \\
\hline Dopamine & $43 \pm 6$ & $181 \pm 7$ \\
Dobutamine & $43 \pm 5$ & $185 \pm 8$ \\
Isoproterenol & $37 \pm 4$ & $186 \pm 9$ \\
\hline 'Mean \pm SEM & &
\end{tabular}

pressure was unchanged from control during the drug infusions. Control hematocrit averaged $35 \%$.

\section{DISCUSSION}

Important differences of the hemodynamic effects of isoproterenol, dopamine and dobutamine in anesthetized puppies have been shown. Whereas cardiac output was increased $(P<0.1)$ from control at the highest dose of dopamine and dobutamine tested, cardiac output was increased only slightly by isoproterenol at the highest dose tested. Isoproterenol produced a greater increment of heart rate than either dopamine or dobutamine to achieve a similar increase $(10 \%)$ of cardiac output. Indeed, when the change in cardiac output was normalized to a $20 \%$ increase in heart rate, cardiac output was slightly reduced by isoproterenol. Because myocardial efficiency decreases as the ratio of heart rate to cardiac output increases, the marked chronotropic effect of isoproterenol may be detrimental to myocardial function (16).

In this study, systemic arterial mean blood pressure was increased more by dopamine than by dobutamine whereas systemic arterial mean blood pressure actually was decreased by isoproterenol. Similarly, while dopamine increased systemic vascular resistance, systemic vascular resistance was unchanged from control by dobutamine and isoproterenol. The effect of dopamine upon blood pressure and systemic vascular resistance can be explained by the drug's $\alpha$-adrenergic effect, particularly at moderately high and high doses $(>10 \mu \mathrm{g} / \mathrm{kg} / \mathrm{min})$ (11). Isoproterenol and dobutamine have little, if any, $\alpha$-adrenergic effect.

Renal artery blood flow was increased consistently by dopamine, but was unchanged by dobutamine and decreased by isoproterenol. The marked increase of renal blood flow produced by dopamine has been attributed to selective "dopaminergic" recep- 
tor stimulation in the kidney leading to reduced renal vascular resistance. This dopaminergic effect can be blocked by haloperidol $(10-12,25,26,28,35)$. In this study, however, renal vascular resistance was unchanged by dopamine suggesting that changes in renal blood flow reflected changes of blood pressure and cardiac output rather than a selective reduction of renal vascular resistance.

Isoproterenol is a direct $\beta_{1}$ and $\beta_{2}$-adrenergic agonist. It has chronotropic, inotropic, and peripheral vasodilatory effects. Because of the generalized vasodilatory effect, blood flow may decrease to vital areas such as the kidney, mesentery, and brain because of preferential increase of blood flow to muscle and skin $(13,16)$.

Dopamine is a direct and indirect $\beta_{1}$-adrenergic agonist $(10,11$, 28). At moderately high and high doses $(>10 \mu \mathrm{g} / \mathrm{kg} / \mathrm{min})$ it has peripheral $\alpha$-adrenergic effects (10). In adult animals, at low and moderate doses $(2-10 \mu \mathrm{g} / \mathrm{kg} / \mathrm{min})$, its dopaminergic effect causes decreased renal, splanchnic, coronary, and cerebral vascular resistance $(10-12,25,26,28,35)$. Thus, as dopamine augments cardiac output, blood flow is increased preferentially in vital vascular beds. It has been demonstrated previously that the isolated myocardium of young puppies is relatively insensitive to the inotropic effect of dopamine (5). The authors speculated that this insensitivity was a function of decreased levels of releasible norepinephrine in the ventricular myocardium of young puppies (8). Despite the relative insensitivity of the isolated myocardium to dopamine, the intact cardiovascular system is responsive to this drug even in puppies. This suggests that the cardiovascular system of the intact animal may be more sensitive to the direct $\beta_{1}$ adrenergic effects of dopamine than the isolated myocardium or that norepinephrine released from extracardiac sympathetic nerves may increase myocardial contractility. However, the response of cardiac output in puppies to isoproterenol, dopamine, and dobutamine is less marked than the response of adult dogs to these sympathomimetic agents (6). Indeed, when we examined the response of very young puppies (less than 10 days old), these drugs produced no significant change in cardiac output. Systemic arterial blood pressure, heart rate, and renal blood flow, however, changed in a similar manner in both very young puppies and adult dogs (6).

Tuttle and Mills (33) synthesized dobutamine in an attempt to find an inotropic agent with the $\beta_{1}$-adrenergic but without the $\beta_{2}$ adrenergic action of isoproterenol and without the $\alpha$-adrenergic activity of dopamine. The results of this study are consistent with those of others who found dobutamine to have an inotropic effect with less chronotropic effect than isoproterenol and less hypertensive effect than dopamine $(2,9,21,22,27,31)$.

Based upon the results of this study, dopamine and dobutamine possess potential therapeutic advantages over isoproterenol in augmenting cardiac output and maintaining or increasing renal artery blood flow in young animals.

\section{REFERENCES AND NOTES}

1. Akhtar, N., Mikulic, E., Cohn, J., and Chaudhry, M.: Hemodynamic effect of dobutamine in patients with severe heart failure. Amer. J. Cardiol., 36: 202 (1975).

2. Beregovich, J., Bianchi, C., Rubler, S., Lomnitz. E., Cagin, N., and Levitt. B.: Dose related hemodynamic effects of dopamine in congestive heart failure. Amer. Heart J., 87: 550 (1974).

3. Crexells, C., Bourassa, M. G., Biron, P.: Effects of dopamine on myocardial metabolism in patients with ischemic heart disease. Cardiovasc. Res., 7: 438 (1973).

4. Dopamine for treatment of shock. Med. Lett., 17: 13 (1975).

5. Driscoll, D. J., Gillette, P. C., Ezrailson, E. G., and Schwartz, A.: Response of the neonatal canine myocardium to dopamine. Pediat. Res., 12: 42 (1978).

6. Driscoll, D. J., Gillette, P., Lewis, R., Hartley, C., and Schwartz, A.: The comparative hemodynamic effects of isoproterenol, dopamine, and dobutamine in puppy and adult dog. (abstract) (Proceedings of the American Academy of Pediatrics Scientific Sessions (Cardiology), New York, October, 1977).

7. Franklin, D. L., Schlegal, W., and Rushmer, R. F.: Blood flow measurement by Doppler frequency shift of backscattered ultrasound. Science, 134: 564 (1961).

8. Gauthier, P., Nadeau, R., and DeChamplain, J.: The development of sympathetic innervation and the functional state of the cardiovascular system in newborn dogs. Can. J. Physiol. Pharmacol., 53: 763 (1975).

9. Gillespie, T., Ambos, H., Sobel, B., and Roberts, P.: Effects of dobutamine in patients with acute myocardial infarction. Amer. J. Cardiol., 39: 588 (1977).

10. Goldberg, L.: Cardiovascular and renal actions of dopamine: potential clinical applications. Pharmacol. Rev., 24: 1 (1972).

11. Goldbergt, L.: Dopamine-clinical uses of an endogenous catecholamine. N. Engl. J. Med., 291: 707 (1974).

12. Goldberg. L.. McDonald, R. H., and Zimmerman, A. M.: Sodium diresis produced by dopamine in patients with congestive heart failure. N. Engl. J. Med., 269: 1060 (1963).

13. Goodman, L., and Gilman, A.: The Pharmacological Basis of Therapeutics. 4th Edition, (The MacMillan Co., New York, 1970).

14. Gunnar, R., Loeb, H. Pietras, R., Ortiz, J., and Tobin, J.: Hemodynamic effects of dopamine compared to norepinephrine and isoproterenol in clinical shock. (abstract) Circulation, 37 (suppl. VI): 91 (1968).

15. Halloway, E. L., Schultz, C. S., Stinson, E. B., and Harrison, D. C.: Comparison of circulatory effects of dopamine and isoproterenol immediately following cardiac surgery. (abstract) Circulation 48 (Suppl IV): 177 (1973).

16. Halloway, E. L., Stinson, E. B., Derby, G. C., and Harrison, D. C.: Action of drugs in patients early after cardiac surgery. I. Comparison of isoproterenol and dopamine. Amer. J. Cardiol., 35: 656 (1975).

17. Hartley, C. J., and Cole, J. S.: An ultrasonic pulsed Doppler system for measuring blood flow in small vessels. J. Appl. Physiol., 37: 626 (1974).

18. Hartley, C., Hanley, H., Lewis, R., and Cole, J.: A multichannel directiona pulsed Doppler flowmeter. (Proc. 27th A.C.E.M.B., 339, Philadelphia. Pennsylvania, October, 1974).

19. Hartley, C. J., Lewis, R. M., Hanley, H. G., and Cole, J. S.: Regional blood flow sensing in rats: A preliminary report. (Proceedings of Ilth International Conference on Medical and Biological Engineering, 420-421, Ottawa, Canada August 1976).

20. Holzer, J., Karliner, J. S., O'Rourke, R. A., Pitt, W., Ross, J.: Effectiveness of dopamine in patients with cardiogenic shock. Amer. J. Cardiol., 32: 79 (1973)

21. Kersting, F., Follath, F., Moulds, R., Mucklow, J., McClog, R., Sheares, J., and Dollery, C.: A comparison of cardiovascular effects of dobutamine and isoprenaline after open heart surgery. Brit. Heart J., 38: 622 (1976).

22. Loeb, H. S., Bredakis, J., and Gunnar, R. M.: Superiority of dobutamine over dopamine for augmentation of cardiac output in patients with chronic low output cardiac failure. Circulation, 55: 375 (1977).

23. Loeb, H. S., Winslow, E. B., Rahimtoola. S. H., Rosen, K. M., and Gunnar, R $M$.: Acute hemodynamic effects of dopamine in patients with shock. Circulation, 44: 163 (1971).

24. MacCannel, K. L., McNay, J. L., Mayer, M. B., and Goldberg, L.: Dopamine in the treatment of hypotension and shock. N. Engl. J. Med., 275: 1389 (1966)

25. McDonald, R. H. Goldberg, L., McNay, J. L., and Tuttle, E. P.: Effects of dopamine in man: Augmentation of sodium excretion glomerular filtration rate, and renal plasma flow. J. Clin. Invest., 43: 1116 (1964)

26. McNay, J. L., McDonald. R. H., and Goldberg, L. I.: Direct renal vasodilatation produced by dopamine in the dog. Circ. Res., 16: 510 (1965).

27. Meyer, S., Curry, G., Dousby, M., Twieg, D., Porkey, R., and Willerson. J.: Influence of dobutamine on hemodynamics and coronary blood flow in patients with and without coronary artery disease. Amer. J. Cardiol., 38: 103 (1976).

28. Reid, P., Thompson, W. L.: The clinical use of dopamine in the treatment of shock. Johns Hopkins Med. J., 137: 276 (1975).

29. Rosenblum. R., and Frieden, J.: Intravenous dopamine in the treatment of myocardial dysfunction after open heart surgery. Amer. Heart J., 83: 743 (1972).

30. Rosenblum, R., Razzakttai, A., and Lawson, D.: Dopamine in man: Cardio-renal hemodynamics in normotensive patients with heart disease. J. Pharm. Exptl. Ther., 183: 256 (1972).

31. Sakamoto, T., and Yamada, $T$.: Hemodynamic effects of dobutamine in patients following open heart surgery. Circulation. 55: 525 (1977).

32. Talley, R. C., Goldberg, L. I., Johnson, C. E., and McNay, J. L.: A hemodynamic comparison of dopamine and isoproterenol in patients in shock. Circulation. 39: 361 (1969).

33. Tuttle, R., and Mills, J.: Dobutamine: Development of a new catecholamine to selectively increase cardiac contractility. Circ. Res., 36: 185 (1975).

34. Winslow, E. J., Loeb, H. S., Rahimtoola, S. H., Kamath, S., and Gunnar, R. M. Hemodynamic studies and results of therapy in 50 patients with bacteremic shock. Amer. J. Med., 54: 421 (1973).

35. Yeh, B. K., McNay, J. L., and Goldberg, L. I.: Attenuation of dopamine renal and mesenteric vasodilation by haloperidol: Evidence for a specific dopamine receptor. J. Pharm. Exptl. Ther., 168: 303 (1969).

36. This work was presented at the Scientific Sessions of the American Academy of Pediatrics, Section on Cardiology, November, 1977. New York, New York.

37. This material was developed by the Section of Myocardial Biology of the National Heart and Blood Vessel Research and Demonstration Center. Baylor College of Medicine.

38. This research was supported in part, by grant \#HL-5756 from the National Institutes of Health. United States Public Health Service and is a grantsupported research project of the National Heart, Lung and Blood Institute. National Institutes of Health, grant \#HL 17269 and Contract HV-52998.

39. This research was supported by David J. Driscoll, M. D., Department of Pediatrics, Texas Children's Hospital, 6621 Fannin. Houston. TX 77030 (USA).

40. Received for publication April 25, 1978.

41. Accepted for publication August 30, 1978. 